\title{
ANÁLISE DE GÊNERO MULTIMODAL: CAPA DE LIVRO DE AUTOAJUDA
}

\section{ANALYSIS OF MULTIMODAL GENRE: BOOK COVER SELF-HELP}

\author{
Julio Neves Pereira ${ }^{1}$ \\ UFBA - Universidade Federal da Bahia
}

\begin{abstract}
RESUMO: O trabalho visa apresentar resultados de análise semiótica da capa de três livros de autoajuda; mostrar os procedimentos de manipulação, verificando, de um lado, como os elementos visuais e verbais se estruturam para efetivar o intento; qual sistema predomina nesse gênero: se o simbólico ou o semissimbólico. Observou que nas capas analisadas o sistema de símbolos sobredetermina o semissimbólico, visto que mobiliza elementos cristalizados que remetem a situações sócio-históricas, produzindo o efeito de sentido identidade (entre enunciador e enunciatário). Assim, neste trabalho, toma-se o uso do símbolo como recurso de manipulação do leitor-enunciatário.
\end{abstract}

PALAVRAS-CHAVE: Autoajuda; Semissimbolismo; Gênero; Símbolo; Multimodalidade, Multissemiótico.

ABSTRACT: The work, based on the contributions of Greimas and Floch, aims to present results of semiotic analysis of the cover of three self-help books, show handling procedures used in establishing the trust deed, checking on the one hand, as the visual elements and verbal are structured to accomplish the purpose; which system prevails in this genre: the semi-symbolic or symbolic. He noted that the analysis covers the system of symbols over determines the semi-symbolic, as it mobilizes crystallized elements that refer to socio-historical, producing the effect of sense identity (between enunciator and enunciatee). In this work, one takes the use of the symbol as resource manipulation of the reader-enunciatee.

KEYWORDS: Self Help; Semi symbolism; Genre; Symbol; Multimodality; Multisemiotic.

\section{Introdução}

As reflexões críticas acerca do sujeito e da realidade são preocupações da semiótica, que, em seus estudos, não perde de vista o que lhe é fundamental: a realidade do objeto textual. No horizonte das análises semióticas, busca-se equacionar os esforços teóricos, partindo sempre da concepção de que, na significação, conversões estruturais ocorrem progressivamente, de modo dinâmico e contínuo. Esse movimento de transformação é tido como o percurso de complexificação, visto que enriquecimentos de ordem gramatical -

\footnotetext{
${ }^{1}$ Professor Doutor da Universidade Federal da Bahia
} 
sintáticos e semânticos - vão sendo agregados às estruturas em seus níveis correspondentes o fundamental, o narrativo e o discursivo.

O princípio basilar, portanto, é o de que fora do texto não há como evidenciar as ideologias incrustadas nas atividades sociais dos sujeitos. É por meio da linguagem em texto que o sujeito se constitui. Nela, as práticas discursivas são desvendadas por meio desse modelo metalingüístico da enunciação. Assim, as relações entre o social e o individual processam-se mediadas pela enunciação, em que se realiza a conversão das estruturas narrativas em discursivas; em que também se estabelece a relação entre texto e condições sócio-históricas.

A enunciação, nesse sentido, regula a relação entre o sistema social da língua e a assunção deste por um sujeito em constante diálogo com o outro: intersubjetividade (BERTRAND, 2003). No momento em que ocorre o revestimento complexo das estruturas mais abstratas, entra em jogo tanto a memória dos sistemas semióticos, suas coerções, a situação sócio-histórica de realização, orientando, no nível da manifestação, os projetos de textualização, que veiculam modos de ver o mundo. Ou seja, a discursivização é guiada por regras sintáticas - actorialização, temporalização e espacialização - e por regras semânticas, cujos produtos são discursos figurativos e temáticos.

$\mathrm{Na}$ análise narratológica, Greimas (1979) distingue dois tipos de relações entre actantes: a que ocorre entre o sujeito e o objeto, a construir o simulacro das ligações existentes entre homem e mundo e a ação transformadora daquele sobre este. A outra relação se dá entre o destinador e o destinatário, actantes da comunicação: o primeiro age sobre o segundo doando-lhe competências, para transformá-lo ou subjugá-lo. Essa ação visa à instituição de um contrato em que o sujeito da enunciação, desdobrado em enunciador e enunciatário, estabelece um jogo de manipulação em que há um fazer persuasivo (enunciador), e um fazer interpretativo do segundo.

Esses actantes da comunicação estão associados um ao outro por meio de uma relação contratual fiduciária regulada tanto pelas intenções da enunciação - fazer com que o sujeito da interpretação aceite como verdadeiro o dizer do enunciador e passe agir conforme essa crença (ou fé) -, como pelas condições sociais inerentes ao ato comunicativo que implicam o emprego de várias estratégias em razão da eficácia comunicativa (fazer crer, querer ou dever, fazer, saber e poder).

$\mathrm{O}$ fato de o efeito de verdade ou de falsidade do discurso, vinculado ao contrato, atrelar-se a um tipo discursivo e a fatores de ordem extralinguística, implica a afirmativa de que o percurso de manipulação (comunicação) orienta-se de acordo com um gênero específico, marcado tanto por fatores internos como externos, voltados para a eficácia comunicativa.

Para Bakhtin (2003, p.281-282, grifos do autor)

Em cada enunciado [...] abrangemos, interpretamos, sentimos a intenção discursiva de discurso ou a vontade discursiva do falante, que determina o todo do enunciado, o seu volume e as suas fronteiras. Imaginamos o que o falante quer dizer, e com essa idéia verbalizada, essa vontade verbalizada (como a entendemos) é que medimos a conclusibilidade do enunciado. Essa idéia determina tanto a própria escolha do objeto (em certas condições de comunicação discursiva, na relação necessária com os enunciados antecedentes) quanto os seus limites e a sua exauribilidade semânticoobjetival. Ele determina, evidentemente, também a escolha da forma do gênero na qual será construído o enunciado [...] 
Isso significa que o enunciador, no ato comunicativo, detém a iniciativa no processo de interpretação, no sentido de que age discursivamente segundo a imagem que faz do outro. Aqui cabe lembrar que os simulacros são imagens, figuras, que intervêm na comunicação a partir de seu caráter necessário e de sua condição de ser algo prévio a qualquer comunicação. Nessa concepção, os simulacros são considerados objetos imaginários determinadores eficazes da relação entre os sujeitos (BARROS, 1996).

Disso resulta um discurso com estilo e composição próprios, adequados aos interlocutores, porque essa atitude implica sobremaneira a particularização, a diferenciação dos aspectos retórico-estilísticos. Vale ressaltar que a adequação implica em manter-se na esfera de determinado gênero, visto que este solicita um destinatário típico e apropriado.

Assim, o ponto de partida é que toda a ação comunicativa visa a um fim determinado: a manipulação. Busca-se por esta ação influenciar o enunciatário aderir a uma crença e a fazer algo. Na relação entre os actantes da enunciação, em que um contrato será a base do relacionamento, o sujeito da persuasão buscará criar identidade com o enunciatário. Tal processo pressupõe que as imagens construídas ajam como modelos a serem incorporados pelo sujeito da interpretação de tal forma que a adesão às imagens estereotipadas significará (como efeito construído) a plena inserção e participação do enunciatário na comunidade imaginária em que circulam valores socialmente especificados.

Os gêneros de características intersemióticas não fogem a tudo isso. Os modos de utilização dos sistemas desses gêneros sincréticos desembocam, necessariamente, também no estabelecimento de novas correlações intersistêmicas. Na correlação existente, em que há coatuação presencial dos sistemas, os imperativos (coerções) de cada modo agem uns sobre os outros, permitindo a atuação interacional. Essa compreensão é importante, porque

As qualidades, as quantidades, as intensidades de cada traço em um agir com outras graduações na formação composicional que vamos considerar como novo arranjo que advém das orientações resultantes da interação sincretizante. Sem montar uma interlocução com esses usos integrativos de sistemas heterogêneos, o tratamento dos objetos sincréticos está condenado à esterilidade. (OLIVEIRA, p. 82)

Essa postulação realizada pela semioticista de que a realização do estudo semiótico do sincretismo da expressão implica a discursivização das escolhas, no plano da expressão, de um enunciador, de um lado permite dar conta dos processos de escolha e usos desse sujeito enunciador, caracterizá-lo, no momento da edificação de seus regimes de interação com o enunciatário, bem como configurar "esses simulacros na imanência do objeto sincrético, como simulacros do destinador e do destinatário no contexto situacional de sua ocorrência sócio-político-cultural”. (Idem)

Desse modo, a análise centrou-se em um corpus composto de três capas de três livros de autoajuda que versam sobre o tema sucesso pessoal e/ou profissional, escritos pelos autores brasileiros Lauro Trevisan, João Dória Junior e Alexandre Henrique Santos. As obras escolhidas são, respectivamente, O poder infinito de sua mente (1980), Lições para vencer (2001) e Você pode conseguir o que quer (2001).

Todos esses enunciadores-autores são homens que simulam serem vencedores, autossuficientes, felizes, empreendedores, sábios, mas, sobretudo, sensíveis aos problemas dos outros, pois têm ações sociais. Apresentam-se ainda como sujeitos voltados para o trabalho; são ecléticos, pois querem que se acredite que transitam em várias áreas do conhecimento. Outro simulacro é o de serem homens que possuem ao mesmo tempo qualidades racionais e espiritualistas. 
Desse modo, para exercer um poder de captação do enunciatário, o enunciador constrói sua imagem segundo a conjuntura ideológica, com base no individualismo, a qual parece estar projetada no discurso como um estereótipo motivador da identificação. O livro é uma fórmula para resolver os problemas dos indivíduos. Assim, é construído segundo princípios discursivos que levam em conta diversos fatores contextuais e textuais a fim de conseguir eficácia comunicativa.

Desse modo, tendo como objeto de análise o gênero capa, pergunta-se: que estratégias são utilizadas neste gênero para persuadir o enunciatário que (supostamente) comprará o livro?

Objetiva-se, portanto, nesse trabalho, analisar os procedimentos de manipulação construídos nas capas de autoajuda a partir da organização sincrética (para nós também multimodal ou multissemiótica) de elementos visuais e verbais, observando, também, no plano da expressão, qual sistema predomina nesse gênero, se o simbólico ou o semissimbólico, e se tal predomínio efetiva-se como estratégia enunciativa de manipulação.

Nessa perspectiva, por conseguinte, a estrutura do gênero capa a ser descrita neste trabalho será o discurso, tendo em vista as estratégias de persuasão presentes nesse gênero multissemiótico (multimodal), em que, no plano da expressão, o verbal e o visual dialogam.

\section{Signo, símbolo e semissímbolo}

Discutir a diferenciação entre símbolo e semi-símbolo é retornar à discussão sobre arbitrariedade sígnica. O signo comporta dois constituintes básicos: significante e significado. Sua relação se dá por um processo de arbitrariedade. Não há entre tais elementos nenhum tipo de motivação no sentido de que um, necessariamente, motive a existência do outro: o significado não evoca naturalmente um significante, nem este faz o mesmo em relação ao conteúdo. De acordo com Saussure (1973, p.81)

O laço que une o significante ao significado é arbitrário ou então, visto que entendemos por signo o total resultante da associação de um significante com um significado, podemos dizer mais simplesmente: o signo lingüístico é arbitrário.

[...] queremos dizer que o significante é imotivado, isto é, arbitrário em relação ao significado, com o qual não tem nenhum laço natural na realidade.

Essa relação intra-sígnica, apesar disso, não resulta de uma ação individual e particular sobre o sistema; longe disso, é determinada por uma instituição social, de modo que o elo entre os elementos origina-se de uma convenção social imposta aos usuários da linguagem. Pode vir a existir, entretanto, um vínculo natural entre a parte material e concreta do signo e a sua parte abstrata, resultando em símbolo que "[...] tem como característica não ser jamais completamente arbitrário; ele não está vazio, existe um rudimento de vínculo natural entre o significante e o significado" (1973, p.82).

$\mathrm{O}$ estreitamento gera motivação. Quando significado e significante amalgamam-se, tornam-se unos por uma relação de contiguidade. Assim, os símbolos, embora sejam passíveis de receberem um sentido de conteúdo, e por isso, sejam interpretáveis, são, entretanto, monoplanares (HJELMSLEV, 1975). Quando ocorre a união entre forma expressiva e conteúdo, os planos do símbolo conformam-se um ao outro de tal forma que é impossível analisá-los separadamente, já que, nessa operação, perde-se o caráter 
diferencial dos planos. Ou seja, para materializar o conceito de cristianismo, deve-se recorrer tão somente à figura cruz, caso contrário, perde-se o conceito; fato semelhante ocorre com as figuras foice e martelo, que materializam o conceito comunismo; isso pode ocorrer também com a dança em círculos das abelhas, os quais figurativizam o sentido de distância e de direção de algum alimento. Não há, pois, no caso do símbolo, a discriminação entre o que é conteúdo e o que é expressão, caso houvesse, sua essência seria rompida, porque

[...] Parece existir um parentesco essencial entre as peças interpretáveis de um jogo e os símbolos isomorfos, pois nenhum deles admite a análise ulterior em figuras, que é característica dos signos [...] (1973, p. 117).

Devido a essa condição de ser um objeto indecomponível em figuras - fator básico para a conformação de um sistema -, considera-se o símbolo uma grandeza, por suas limitações internas, que permite ao analista uma única interpretação em determinado contexto sócio-cultural (GREIMAS, 1979). Dessa maneira, compreende-se que o símbolo, por sua natureza motivada, é um não-signo, portanto, um objeto não semiótico.

Por outro lado, uma ação consciente e criativa sobre a materialidade pode produzir certa motivação entre os constituintes de um signo, sem, entretanto, torná-lo um símbolo nos moldes já descritos. É o caso dos semi-símbolos. Há signos em que se observa que o conteúdo está relacionado à expressão de um modo especial, não porque há algum tipo de vínculo natural que os aproximem, mas porque a expressão está correlacionada, homologada, a um conteúdo por meio de uma construção racional, resultando em identidade dos planos, como acontece nas expressões poéticas, por exemplo, em que sons, sintaxes e os conteúdos encontram-se uníssonos, presentificando determinado objeto.

O sistema de semi-símbolos, diferentemente do sistema de símbolo, na produção de significação, resulta, portanto, da correlação arbitrária entre significante e significado. Esse sistema surge desse jogo em que as articulações do significante e do significado estão unidas clara e distintamente para a criação da ilusão referencial, assumida como verdadeira, "cuja sacralidade fica assim fundamentada em sua materialidade" (GREIMAS, 1975). O que significa que

[...] a motivação poética (portanto, semi-símbolo), (é) suscetível de ser definida como a realização das estruturas paralelas e comparáveis que estabelecem correlações significativas entre os dois planos da linguagem fornecendo, com isso, um estatuto específico aos signos-discursos assim manifestados. (1973, p. 29)

Essa conversão de estruturas virtuais em estruturas atuais, de acordo com Lopes (1993), seguida de homologação das categorias do plano da expressão e as do plano do conteúdo, dá-se pelo incessante processo de re-configuração das relações sígnicas internas e arbitrárias, em que categorias vão sendo correlacionadas uma a uma, estabelecendo relação semimotivada entre significante e significado. O resultado desse processo de abertura (construção semi-simbólica) é, de um lado, a ruptura com conteúdos cristalizados, arraigados à cotidianidade; de outro, a instauração de uma nova consciência do objeto, o redimensionamento do mundo por meio de diversos procedimentos discursivo-textuais, e a consequente aquisição de um novo saber. Esse processo, portanto, não visa à produção do reconhecimento do mundo, de um discurso altamente referencializado em que se cria o efeito de sentido ser o real, fechado e centrado no já dito por meio de figurativização semântica. 
De outro modo, é preciso reconhecer que, em alguma medida, o símbolo no processo de discursivação tem, em muitos gêneros importância por isso deve ser considerado nas análises. Barthes (2003) alerta que se deve atribuir ao símbolo importância fundamental para o estudo dos discursos, já que é constituído pela superposição do significado e do significante, em que

[...] Existe a consciência de uma espécie de relação vertical entre a cruz e o cristianismo: o cristianismo está sob a cruz, como massa profunda de crenças, de valores, e de práticas mais ou menos disciplinadas ao nível de sua forma. A verticalidade da relação traz duas consequiências: por um lado, a relação vertical tende a parecer solitária: o símbolo parece manter-se de pé no mundo, e mesmo quando se afirma que ele abunda, é sob a forma de uma "floresta", isto é, de uma justaposição anárquica de relações analógicas: a forma se parece (mais ou menos, mas sempre um pouco) [...] com o conteúdo, como se ela fosse em suma produzida por ele, de modo que a consciência simbólica recobre talvez um determinismo mal liquidado: existe pois o privilegio maciço da semelhança (mesmo quando se sublinha o caráter inadequado do signo). [...] o símbolo dispõe de um prestígio mítico, o da "riqueza": o símbolo é rico, eis por que, dizem, não se pode reduzi-lo a um 'simples signo' (pode-se hoje duvidar da 'simplicidade' do signo): a forma é nele incessantemente transbordada pelo poder e o movimento do conteúdo; é que de fato, para a consciência simbólica, o símbolo é muito menos uma forma (codificada) de comunicação do que um instrumento (afetivo) de participação. [...] (1973. p. 44).

Dessa visão, cumpre reter, de um lado, que a todo símbolo subjaz uma massa de crenças, de valores e de práticas conformadas à forma; de outro, que ele tem a função de ser um instrumento efetivo de participação. Instrumento que deve ser visto como uma estratégia importante na operação de persuasão, porque, a partir do símbolo, mobilizam-se valores e crenças. Possibilita ao enunciador criar vínculos efetivos com o enunciatário, ao não criar o efeito de sentido afastamento total do real e de seu redimensionamento; conseqüentemente, não afeta a percepção do sujeito da interpretação, nem lhe abre significâncias; mas, ao contrário, porque fecha sentidos, delimita a percepção. Persuasivamente, "o aspecto simbólico de um ato será tanto mais facilmente aceito quanto menos plausível for outra interpretação" (PERELMAN \& OLBRECHTS - TYTECA, p. 380).

Por isso, é importante que se encare sua aparição em determinados discursos, eles

[...] desempenharão um papel muito diferente e terão um significado muito diferente daqueles que não o são: eles reagem de uma maneira mais violenta sobre os seres que lhes são solidários, que são responsáveis por eles. As técnicas de ruptura ou de refreamento entre ato e pessoa não poderão ser utilizadas quando o ato é considerado simbólico, porque tais técnicas implicam certa racionalidade. (PERELMAN \& OLBRECHTS - TYTECA, 2002, p.379)

O sujeito, ao recorrer ao símbolo, tem em suas mãos uma estratégia que aumenta o seu poder persuasivo. Esse poder advém de sua propriedade de ser mais concreto e manipulável que o simbolizado, o que lhe confere a capacidade de fazer vir à tona e de imediato o sentido, dando-lhe presença (processo de figurativização). Essa presença tem a 
finalidade de fazer com que o sujeito da interpretação reconheça os laços que o unem ao enunciador e à temática construída. Assim, neste trabalho toma-se o símbolo como objeto que será estudado no nível discursivo, patamar em que os sentidos são tematizados e revestidos por figuras.

\section{Análises das capas de livros de autoajuda}

As capas dos livros ${ }^{2}$ se apresentam informações claras e enfáticas. Nelas, as qualidades do livro (de seu conteúdo) são apresentadas, persuasivamente, em um discurso cristalino, figurativo, portanto, altamente referencializado. Mesmo assim, ao proceder à análise dessas imagens deve-se considerar que o texto visual sempre tende a ser biplanar (FLOCH,1990), que permite relações categoriais entre os planos. De qualquer modo, embora isso esteja evidenciado na natureza da imagem, essa relação sempre tende para certo fechamento que, no dizer de Lopes (1993), virá a veicular sentidos únicos.

\section{Análise da Capa1}

Na Capa 1, apresentam-se um plano de fundo constituído por imagens icônicas, e um primeiro plano constituído basicamente por caracteres tipográficos (letras). No plano de fundo, encontram-se pontos brancos concentrados e difusos, de tamanho e de forma irregulares, a constituir círculos concêntricos dispostos de modo que os maiores englobem os menores a partir de um centro branco (núcleo), único e denso.

\footnotetext{
${ }^{2}$ Os objetos de análise serão tratados por Capa 1, referente ao livro $O$ poder da mente; Capa 2, referente ao livro Lições para vencer; Capa 3, referente ao livro Você pode conseguir o que quiser. 


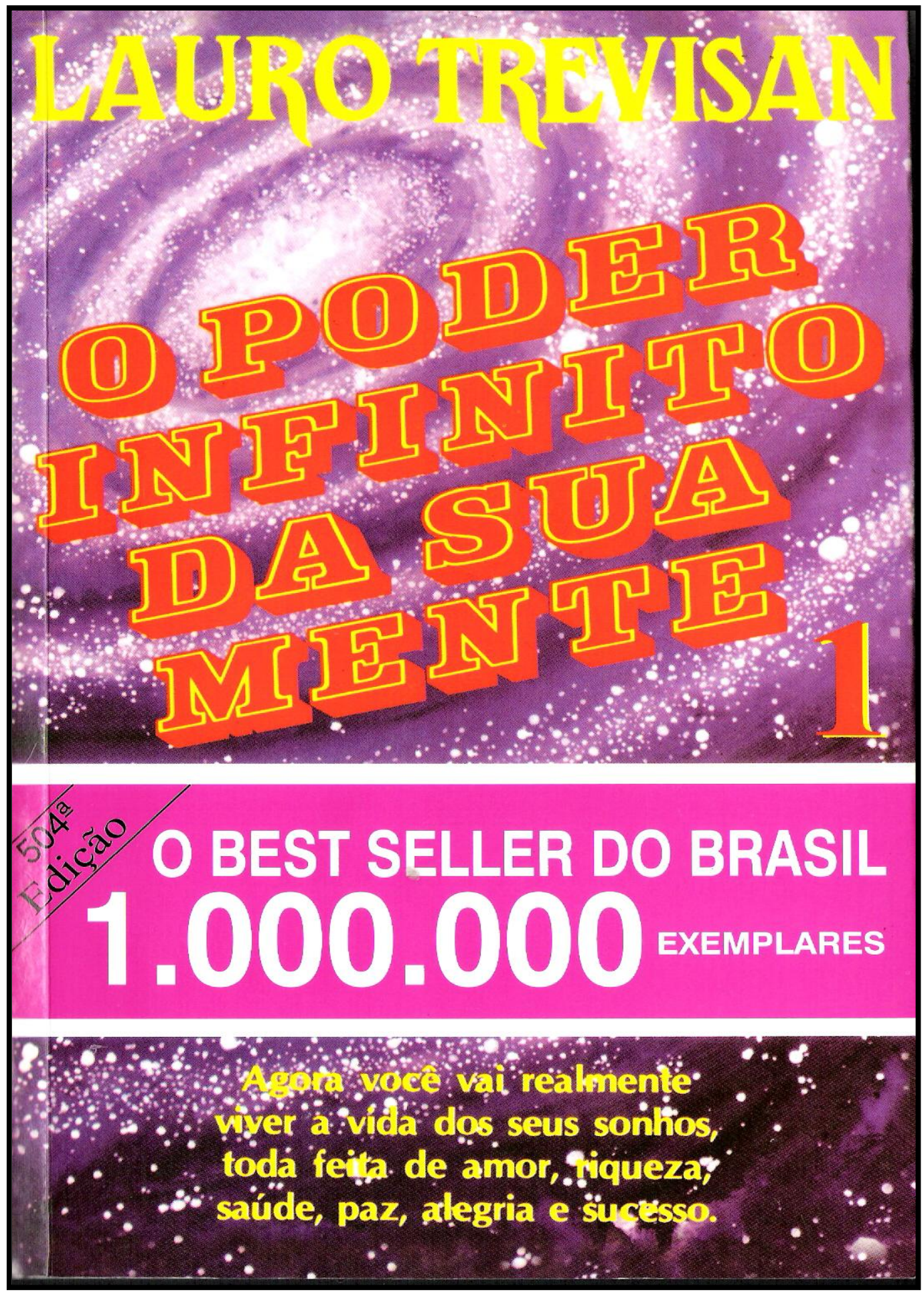

Imagem 1 - Capa 1

Quanto mais próximos do centro, encontram-se mais concentrados, mais densos e com formas pouco definidas, tendendo ao disforme; quando mais afastados do centro, os pontos tornam-se mais dispersos e esparsos, mas com a forma bem definida. Estes pontos brancos se superpõem e se confundem com sua base azul-arroxeada. O efeito dessa disposição é o simulacro de um movimento de expansão constante, que parece irradiar-se, harmonicamente, pois tudo parece girar no mesmo sentido e no mesmo instante. 
Sobrepondo-se a este fundo, e a este se contrastando, há uma faixa retangular vermelho-clara, com bordas brancas. Nela, escritas em cor branca, constam informações como: a qualidade do livro (BEST SELLER DO BRASIL), o número de exemplares vendidos bem destacado pelo tamanho da letra $(770.000)$ e, em cor preta, o número de edições publicadas $\left(331^{\mathrm{a}}\right)$, disposto transversalmente no canto superior esquerdo do retângulo. Essa cinta, pela sua localização e forma, divide o texto-capa em duas partes desiguais: uma alta, de maior extensão, e outra baixa, de menor extensão.

Na parte de cima, próximo ao núcleo, encontra-se, na extremidade (posição marginal superior), o nome do autor, destacado por letras amarelas grandes desenhadas, sobressaindo ao fundo. Um pouco mais abaixo, também se destacando ao fundo e tomando quase toda a extensão da parte alta, encontra-se, inclinado em direção aparentemente para cima, o título do livro, destacado por letras grandes vermelhas e cheias, com bordas amarelas. Observa-se que a inclinação e a presença do amarelo nas bordas criam identidade entre o título da obra e o nome do autor, de modo que os olhos do enunciatário-espectador são obrigados, pela configuração estratégica destes elementos, a relacioná-los de modo indistinto: Lauro Trevisan $=0$ Poder Infinito de sua Mente.

Na parte de baixo, onde a cor de fundo azul-arroxeado assume tonalidade mais escura, e os pontos brancos estão mais dispersos, em menor quantidade, encontra-se um enunciado escrito de forma mais discreta em relação às outras, porque as letras escritas em cor amarela se encontram em caixa-baixa, e o seu tamanho é menor que as letras dos enunciados acima deste.

$\mathrm{Na}$ parte alta, apresentam-se nela elementos que remetem à valorização positiva: é o lugar de maior extensão, presença do nome do autor no topo da capa, presença do nome da obra; é onde se encontra como pano de fundo a imagem do núcleo irradiador; todas as letras dos enunciados presentes nesse espaço se encontram em caixa-alta.

Embaixo, apresentam-se os elementos tipográficos e imagens figurativas (as nuvens esparsas) que remetem à valorização negativa do espaço: dimensão espacial reduzida; fora do eixo central, pequena quantidade de imagens (alguns poucos astros), pouquíssima claridade, as palavras ali presentes estão escritas em caixa-baixa e em letra de tamanho reduzido.

Essa conformação implica a oposição semântica: abundância (excesso) versus escassez (falta), oposição que remete às categorias fundamentais euforia versus disforia. Assim, pretendendo uma análise do semi-símbolo, a categoria espacial alto versus baixo e a categoria tipográfica caixa alta versus caixa-baixa parecem equivaler, no plano do conteúdo, respectivamente, às categorias euforia (abundância) versus disforia (escassez). Essa homologação parece ser validada também pela localização desses elementos, pois, como explica Greimas (apud. AGUILAR,s/d), advindas de uma convenção cultural ou de natureza universal, pode-se, sem preocupação, homologar alto como eufórico e baixo como disfórico.

Analisando tais oposições, verifica-se que a cor amarela além de estabelecer elo entre o enunciatário (leitor) e o enunciador (autor), também indica a possibilidade de mudança topológica em que a compra do livro seria a garantia dessa mudança. Tal mudança está representada pela faixa, a qual, de certo modo, ao mesmo tempo em que demarca os pólos opostos, faz também a intermediação entre eles. Esse valor de mudança encontra eco no enunciado de promessa veiculada ao enunciatário, que está marcado pelo pronome de segunda pessoa VOCÊ.

Além das oposições apresentadas, tipograficamente, dois discursos estão em diálogo nesta capa: o discurso do enunciador-autor e o discurso do editor. O tipo de letra do enunciado presente na cinta (faixa vermelho-rosado) é diferente dos outros, porque ele sugere 
mais formalidade. Suas bordas (as do tipo de letra em questão) parecem realizar uma separação bem definida instalando o discurso publicitário, o qual, por causa da tipografia e das cores presentes nele (branco, preto e vermelho rosado), constitui-se como um discurso mais objetivo em contraposição a um discurso mais subjetivo, presente no título (letras grandes, desenhadas), no nome do autor (desenhada) e no enunciado (letras menores, presença da segunda pessoa, informações de dados numéricos).

Assim, em síntese, a capa deste livro se presta a uma análise semi-simbólica. No entanto, essa configuração significante - círculos concêntricos, formados por pontos claros, profusos e irregulares -, remete à imagem icônica, facilmente reconhecível, espaço sideral: reconhecem-se figuras referentes a astros, galáxia, nuvens e céu. Cada um destes elementos age, neste contexto, como signos que evocam significados sedimentados culturalmente na sociedade. $\mathrm{O}$ conjunto dos elementos não produz um signo, mas um símbolo. Levando em conta a relação do plano da expressão e do conteúdo, como já se disse mais acima, as formas descritas são a reprodução bastante aproximada (mimeses) do espaço sideral (do universo), em que se reconhecem astros, céus e nuvens.

As figuras que compõem o espaço sideral (figura de fundo) agem, neste contexto como símbolos que evocam significados sedimentados culturalmente na sociedade; fazem com que o enunciatário associe o universo à idéia de origem (caos), de organização (cosmo), de infinito e de mistério, não por uma relação arbitrária, mas motivada.

Essas imagens remetem, por associação (portanto, quase que automaticamente), a conteúdos já dados. As esferas (círculos concêntricos), no conjunto, representam a expansão ilimitada de uma força a partir de um centro e simbolizam o céu com seu movimento permanentemente circular, ao mesmo tempo em que projetam outros significados relacionados a céu, ele próprio um símbolo que expressa, segundo Chevalier e Gheerbrant (2002), quase que universalmente, a crença em um ser divino celeste, criador do universo e responsável pela fecundidade; representa também a manifestação direta do poder, pois, no senso comum, o simples fato de ser elevado, de encontrar-se em cima ou acima (de), equivale, necessariamente, a ser poderoso, ter sucesso (não se fala de um sujeito de sucesso indicando-o abaixo de quem fala, mas olhando para cima).

Os astros também remetem a significados simbólicos. Em geral, participam das qualidades de transcendência e de luz que caracterizam o céu, fixando o sentido de regularidade inflexível, comandada por uma razão natural e misteriosa ao mesmo tempo. Esses significados, apesar de apontarem para uma dimensão mais inconsciente, não deixam de carregar neles significados do senso comum. As pessoas olham o céu como algo superior, misterioso, constituído por uma força capaz de resolver problemas ou de ocasioná-los (o religioso olha para cima, e, ajoelhado, para evocar a força de seu deus; o crente fervoroso faz o mesmo ao agradecer uma dádiva alcançada ou para pedir ajuda). $\mathrm{O}$ alto sempre remete ao significado da ascensão (subir na vida/ ascender na carreira/ Para o alto e avante/ olhar para frente e para cima sempre...).

De modo geral, o enunciatário, ao entrar em contato com estes elementos visuais que compõem o texto-capa, faz a associação com os significados previsíveis: poder, infinito, mistério. Significante e significado identificam-se e tornam-se inseparáveis, e o signo já não pode ser re-fundado, pois perde sua arbitrariedade. O objeto construído, na mensagem, não é afastado do real, para que se produza o efeito de desreferencialização; não se estabelece uma ruptura entre o objeto e o seu referente, mas simplesmente o reforço e a cristalização dos sentidos, o que leva o enunciatário ao reconhecimento do objeto, sem operar reflexão.

Os significados suscitados pelas imagens de fundo são reforçados pelo próprio título que as sobrepõe. A relação estabelecida entre os signos verbais e os signos visuais é de 
contigüidade, pois o título fecha o sentido das figuras e elas reforçam o significado do título. Há uma homogeneidade que faz com que as qualidades do espaço sideral (significados como poder, mistério) tornem-se qualidades da mente. Assim, a ilustração do universo pretende ser uma metáfora (figurativização) do funcionamento da mente: o poder da mente equivale ao poder do universo.

O enunciador coloca-se, com a utilização de tais recursos, na posição de ser o sujeito que detém o saber do mistério, como sugerem título e subtítulo. No entanto, não se trata de uma metáfora criativa nem criadora, mas de uma catacrese, uma vez que essa relação estabelecida analogicamente é usual e corrente. Portanto, o significado é fechado, as figuras presentes na capa não se abrem para outras possibilidades de significação, separadamente ou em conjunto, a não ser às que se quer fixar no contexto.

\section{Análise as Capa 2}

Na Capa 2, como na capa anterior, observam-se determinadas homologações, mas que não chegam a caracterizar a ilustração como uma construção de um novo ponto de vista. Nela também se encontram um primeiro plano e um plano de fundo, o qual está dividido em duas partes, tomando-se como base a presença de um espaço escuro que corta a capa transversalmente em uma linha sinuosa. Com isso, obtêm-se, igualmente, as duas categorias: alto e baixo.

$\mathrm{Na}$ parte alta, encontram-se formas brancas, irregulares, que parecem estar se movimentando, de maneira a constituir um espaço central circular de fundo azul. Essas formas são reconhecidas como nuvens brancas sobre o céu azul. As nuvens que se encontram adensadas e em maior quantidade são as que estão próximas da linha divisória da capa; nessa parte, a tonalidade é mais escura. $\mathrm{O}$ adensamento e a tonalidade escura causam o efeito de sentido pesado. Já, as nuvens que se encontram menos adensadas, mais esparsas são as que se encontram próximas à extremidade superior da capa; estas são mais claras. A condição de estarem mais esparsas, menos adensadas e mais claras cria o efeito de sentido leveza, e simula o movimento de abertura do céu.

Na parte de baixo, encontram-se pedras arredondadas de diferentes tamanhos, justapostas umas às outras de modo que, quanto mais próximo da margem inferior da capa, maiores e mais arredondadas elas são; quanto mais próximas do céu, menores e menos esféricas se tornam. 
CASA, Vol.10 n.2, dezembro de 2012

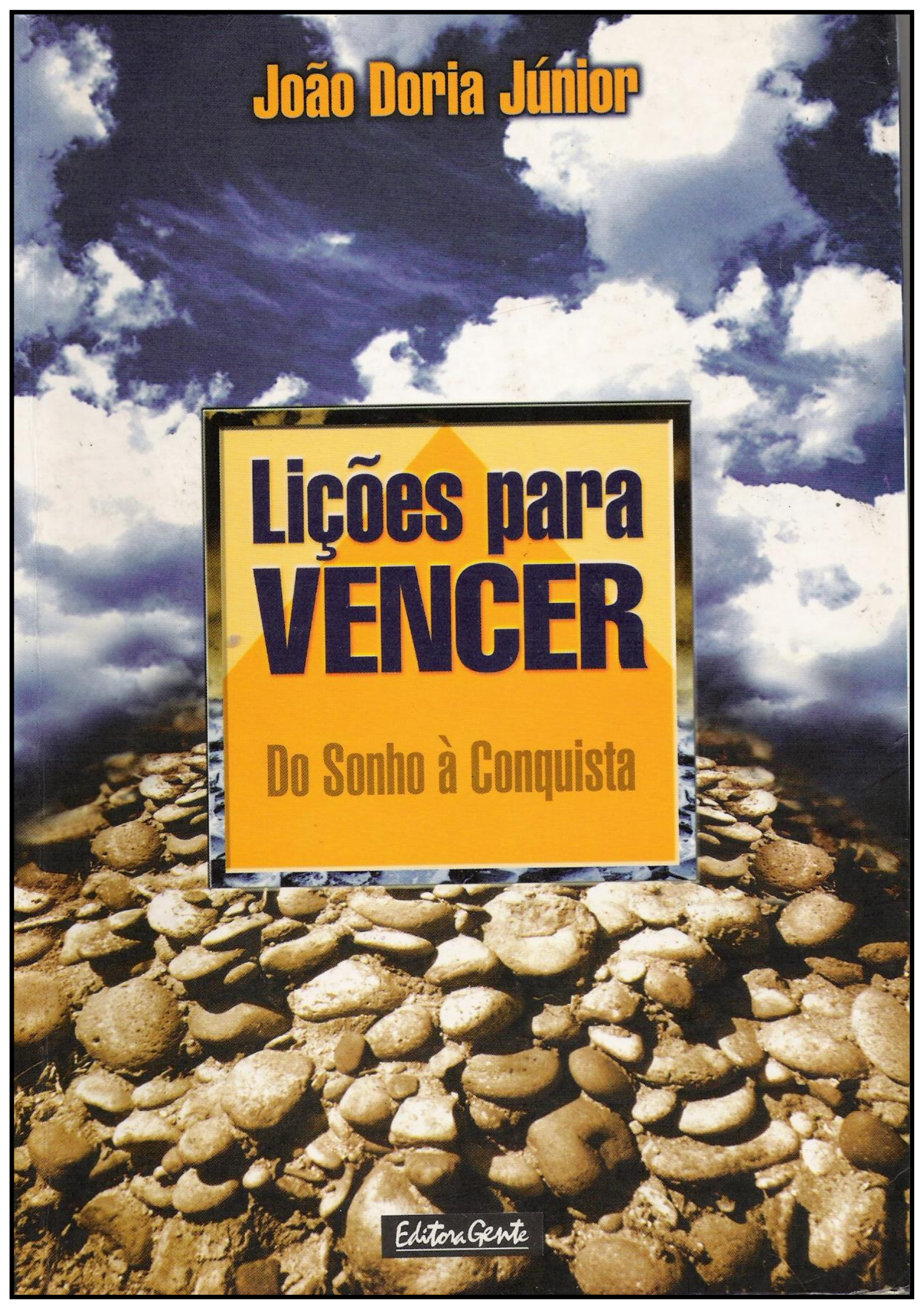

Imagem 2 - Capa 2 
Com essa disposição das pedras, associada ao modo como a luz incide sobre elas - maior incidência de luz ocorre no centro do conjunto de pedras e a menor incidência nas periferias (sombra) -, juntamente Esse efeito advém do formato triangular da imagem, formato conseguido com a ausência de luz nas extremidades e com a progressiva diminuição do tamanho das pedras, bem como da perda de seu formato arredondado, à medida que se aproxima da parte média da capa em direção ao alto (céu). Essa configuração remete ao efeito de sentido caminho penoso a ser enfrentado, uma vez que o signo pedra evoca, no contexto, significados tais como os de dureza e obstáculo.

Esse plano de fundo dialoga com o plano que lhe sobrepõe. Na extremidade superior do primeiro plano, encontra-se o nome do autor escrito em amarelo-ouro, bem próximo ao espaço arredondado, no qual as nuvens estão menos adensadas, simulando um céu limpo e aberto. O nome do autor escrito em amarelo-ouro ganha bastante destaque porque fica praticamente envolto das nuvens brancas, que funcionam como simulacro de auréola (do autor), conferindo-lhe brilho e prestígio.

$\mathrm{Na}$ extremidade oposta, encontra-se um pequeno retângulo preto, centralizado e sobreposto às pedras maiores, parte que recebe bastante luz, simulando o início da caminhada. Nele há o nome da editora, escrito em letra cursiva branca e sublinhado por um traço também branco. Esse logotipo, cujas palavras parecem ser escritas à mão, cria o efeito de sentido empresa sensível às questões do homem, efetivando, por sua vez, uma espécie de relação com o nome da editora: Gente, portanto, capaz de indicar o caminho do sucesso.

Entre o nome do autor (marginal superior) e o nome da editora (marginal inferior), verifica-se a existência, na posição central, de um quadrado, no interior do qual existe um triângulo amarelo ouro, cujo cume está voltado para cima em direção ao nome do autor e ao espaço circular azul (o céu). Sobreposto ao triângulo está o título do livro, escrito com letras grandes em azul-celeste. Na base da figura geométrica, está o subtítulo, escrito com letras menores em amarelo-esverdeado. A posição do quadrado faz parecer que o triângulo integra a montanha de pedra, simulando ser seu pico (cume).

Pela descrição pode-se afirmar que há, como na capa do primeiro livro, uma construção mínima semi-simbólica dos elementos que compõe a capa. Nela, encontrou-se a categoria topológica: alto versus baixo. No alto, estão o nome do autor, o céu e o movimento de dispersão de nuvens, que, no senso comum, remete ao significado tempo bom, melhoria do tempo. São sentidos positivos, eufóricos. Na parte de baixo, encontram-se terra, pedras, montanha, que remetem a significados como os de caminhada penosa, dureza, obstáculos. Assim, homologam-se: alto X baixo :: euforia X disforia :: céu X terra (:: vitória X derrota).

Como na capa anterior, também se observam determinadas figuras que carregam uma carga semântica cristalizada, pois evocam sentidos conhecidos. Assim, ao enunciatário não é proposto um novo ponto de vista dos objetos, mas apenas seu reconhecimento. A capa foi construída, estrategicamente, por meio de símbolos: as pedras, o quadrado e o triângulo. Pelo modo como estão organizados tais figuras, fazem com que se associe a esse conjunto de imagem a idéia de montanha, que, de acordo com Chevalier e Gheerbrant (2002), devido à sua posição vertical, próxima do céu com o vértice apontando para este, remete à simbologia da transcendência e ascensão, sentidos presentes também na Capa 1, mas por outro revestimento.

A montanha, por exemplo, é utilizada como símbolo da vitória, basta lembrar a bandeira colocada no seu pico por um homem que venceu os obstáculos. O triângulo com o seu vértice para cima, por representar uma montanha, simboliza, também, a elevação em sentido ao céu, indicando que este (e por extensão, a montanha) é o meio de entrar em relação com a Divindade, simbolizando o retorno ao princípio, como afirma os estudiosos de 
símbolos. Entretanto, contraditoriamente, levando em consideração a simbologia das figuras geométricas: triângulo e quadrado, o vértice do triângulo encostado no quadro simboliza também a possibilidade de romper o obstáculo, visto que o quadrado simboliza, entre outras coisas, a estagnação, a solidificação; e o triângulo, a superação disso. Essa relação opositiva também é encontrada entre céu e montanha, os quais indicam, simbolicamente, a oposição: dinâmico versus estagnação.

Depreende-se, que o trajeto da vitória e da ruptura será cumprido com a compra do livro, o qual é posto para o enunciatário como o instrumento de ajuda para a superação dos obstáculos: é possível chegar ao espaço positivo por meio dele e assumir, como o próprio autor, o lugar da vitória, representada pelo amarelo.

Os elementos figurativos que compõem a capa sinalizam, portanto, para uma compreensão simbólica deles. São elementos que não sofrem transgressão, no sentido de que a relação entre o significado e o significante seja uma construção arbitrária. Ao contrário, todos os elementos remetem à relação termo a termo e, por isso, a significados cristalizados, o que permite o seu reconhecimento. Dessa forma, o enunciador ao organizar os elementos visuais não pretende, neste discurso, criar sentidos novos, mas reafirmar os já dados, assim como ocorre na capa anterior.

Observa-se que, de um lado, no discurso da capa, sobressaem imagens estereotipadas que se relacionam aos temas de sucesso, vitória, poder; de outro, além de visarem ao reconhecimento, nos contextos em que aparecem, os símbolos restringem a interpretação, já que as figuras utilizadas tendem a remeter a significados místicos e religiosos: força transcendente, mistério etc. Isso pode indicar que o livro tem um destinatário bastante definido, pois, como afirmam Perelman e Olbrechts-Tyteca (2002), os símbolos só funcionam persuasivamente quando o enunciatário partilha dos significados.

\section{Análise da Capa 3}

Na Capa 3, essa configuração não é diferente, mas encontram-se outras características que fazem com que o seu discurso crie o efeito de sentido menos místico e religioso. A capa apresenta duas disposições topológicas: na primeira, o lado direito e o lado esquerdo; na segunda: alto e baixo. Também apresenta primeiro plano e plano de fundo.

No primeiro plano, registra-se uma divisão, realizada por uma espécie de tarja colorida retangular, disposta longitudinalmente, cujas cores vão do rosa ao verde (no sentido de cima para baixo). Nessa faixa, aparece, no espaço rosado, a figura de uma peça de xadrez: o cavalo. Paralela a essa figura, no flanco esquerdo, está, na parte superior, o nome do livro escrito também verticalmente e em negrito. O tamanho da figura do cavalo no flanco direito e o tamanho dessa sequiência de palavras são proporcionais.

Tais elementos encontram-se na parte alta da capa juntamente com o nome do autor que está mais acima, escrito em cor azul e situado bem próximo à borda (superior). Já se pode dizer que, como nas capas anteriores, a parte superior congrega elementos eufóricos: cavalo, o título e o nome do autor; a disposição entre os elementos cria, espacialmente, a identidade entre a figura do cavalo e a do enunciador, tornando-o, de certo modo, sujeito que já está em ascensão, legitimado, portanto, para doar um saber, como os enunciadores da outras capas. 


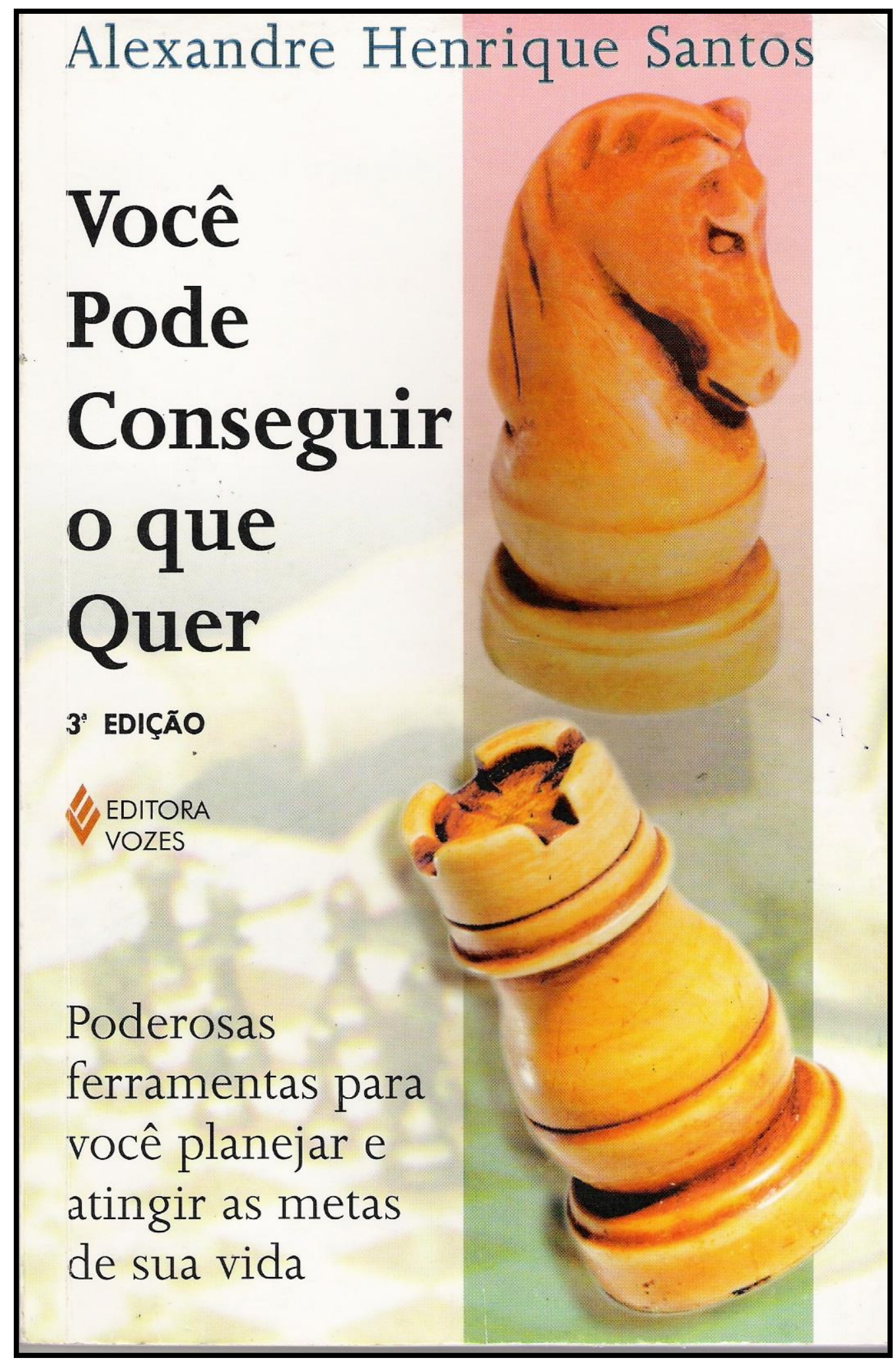

Imagem 3 - Capa 3

Do lado oposto e situado na parte baixa da capa, há outra figura de peça do xadrez, a torre, na mesma linha do nome da editora. Ela está inclinada, o que, em relação ao cavalo, já marca um valor negativo, disfórico, tanto por essa inclinação como por se encontrar na parte baixa da capa. Além disso, no jogo de xadrez, quando um cavalo assalta uma torre, 
praticou-se uma jogada de mestre. Desse modo, essa inclinação da torre, por extrapolar o retângulo, cria um efeito de sentido ruptura, mudança de estado.

Paralelamente à torre, na parte esquerda, apresenta-se outra seqüência de palavras (o subtítulo), cuja disposição formal faz contraste com a do título, tanto pelo tipo e tamanho como pelo tom fraco da cor preta que preenche as letras do subtítulo. O nome da editora, e o número da edição são encontrados na parte mediana da capa, agindo como ponte (ligação) para o lado eufórico, parte superior em que se encontra o sujeito realizado.

No plano de fundo, com pouca nitidez, existe uma figura que remete à imagem de um braço, o qual, por sinédoque, evoca a idéia de pessoa (masculina). A imagem faz parecer que este homem faz uma jogada que parece ser certeira, segura e definitiva, Esse simulacro remete ao conceito de vencedor. E entre a mão e as peças, no lado direito, está o nome da editora, criando o efeito de sentido de elo entre o homem e a riqueza, entre as estratégias e seus resultados. Esse efeito reforça a idéia de que o livro é um instrumento que possibilitará ao enunciatário conseguir atingir suas metas.

A sobreposição do subtítulo sobre o tabuleiro de xadrez, em que estão algumas pedras, estabelece também uma relação associativa entre estes elementos, de modo que as pedras passam a figurativizar (como metáforas visuais) as poderosas ferramentas, que auxiliarão o enunciatário a sair do pólo disfórico rumo ao eufórico. A relação entre figura de fundo e primeiro plano, entre as cores e entre os flancos, constrói o simulacro do autor como um sujeito realizado plena e inequivocamente.

Assim, estão estabelecidas as oposições: alto (cavalo, o nome do autor, título) $\mathrm{X}$ baixo (torre inclinada, subtítulo); ereto (cavalo, título) $\mathrm{X}$ inclinado (torre, subtítulo), letra grande $X$ letra pequena, em que as categorias do plano de expressão, alto, ereto, letra grande, podem ser homologadas às do plano do conteúdo, vitória, sagacidade, habilidade, ascensão (euforia); as categorias: baixo, inclinado, vazio e pequeno podem ser homologadas às categorias derrota, inabilidade, estagnação (disforia).

A capa projeta uma relação em que o enunciatário encontra-se, portanto, em um espaço disfórico (torre inclinada, baixo) e o autor em um espaço eufórico (ereto, vertical, alto), ao mesmo tempo, como nas outras capas, apresenta-se a promessa de mudança de estado, desde que o enunciatário venha a aprender a planejar sua vitória com habilidade, a partir da leitura do livro.

Mas não se pode novamente dizer que a comunicabilidade da capa reside somente na força da semi-simbolização. A força também reside nos sentidos evocados pelas figuras do cavalo, da torre, do xadrez, que são elementos que funcionam como símbolos. No geral, o cavalo representa força, virilidade, assim como a torre; o xadrez evoca, no senso comum, a idéia de racionalidade, cálculo, meticulosidade. Quando se quer representar um homem que planeja com minúcia o seu futuro, o jogo de xadrez é uma boa ilustração, enquanto o de dama já não o é. Além disso, a própria jogada é um símbolo que simula o fato de a vitória ter resultado de estratagemas, o que remete à essência do jogo de xadrez. Segundo o dicionário de símbolos (CHEVALIER e GHEERBRANT, 2002: 966), o jogo de xadrez põe em ação essencialmente a inteligência e o rigor; simboliza o controle e o autocontrole, a aceitação e o domínio da alternância.

Assim, apesar da semimotivação que se observou na capa, na verdade a força da persuasão está no fazer o enunciatário depreender da configuração imagético-verbal apenas uma interpretação, pois os signos se fecham em um sentido. Além disso, o fato de o jogo de xadrez ter sido escolhido para figurativizar o tema da (possibilidade de) vitória já produz a imagem de um enunciatário com certo conhecimento e com determinadas habilidades a serem 
desenvolvidas; assim, os símbolos dirigem-se para alguém que os identificará com certa facilidade, o que aumenta a força persuasiva.

Dessa forma, portanto, as capas revelam um procedimento discursivo: o processo de simbolização, uma vez que, no símbolo, encontram-se depositados valores, crenças e práticas harmonizados em uma forma a qual, em alguma medida, espelha esses conteúdos, já que o plano da expressão e do conteúdo passa a ser homogêneo. A simbolização é, portanto, empregada pelo enunciador como estratégia para a efetivação do contrato, pois o emprego de símbolos evoca, na consciência do enunciatário, os desejos, anseios, colocando o livro como solução dos problemas, e preenchimento das necessidades, no caso de saber vencer as dificuldades, ser feliz, ter sucesso etc.

Como se observou, nessa ação comunicativa, está evidenciado o efeito de sentido identidade enunciador/enunciatário. Tal processo pressupõe que as imagens construídas ajam como modelos a serem incorporados pelo sujeito da interpretação de tal forma que a adesão às imagens estereotipadas significará (como efeito construído) a plena inserção e participação do enunciatário na comunidade imaginária em que circulam valores socialmente especificados.

Maingueneau (2004,p.99) denomina este processo de incorporação em que o sujeito da interpretação passa a ter em seu próprio corpo a qualidade do ethos (corpo) do enunciador. Essa incorporação, no discurso construído nas capas, pode ocorrer pela vontade de estar no lugar do outro.

\section{As cores no discurso da capa}

Ao analisar as capas do ponto de vista de sua constituição simbólica e semisimbólica, observou-se que as cores têm papel discursivo importante no processo de adesão do enunciatário ao contrato proposto pelo enunciador. Elas são apelativas, pungem o olhar do enunciador-espectador, quer por sua própria natureza, quer pela combinação efetuada. Desse modo,

O mundo natural, do "senso comum", na medida em que é logo de saída instruído pela percepção, constitui em si mesmo um universo significante, ou seja, uma semiótica. Ver não é apenas identificar objetos do mundo, é simultaneamente apreender relações entre tais objetos, para construir significações. As percepções fazem sentido na medida em que os objetos percebidos se inserem em cadeias inferenciais que os solidarizam, como se infere o fogo a partir da fumaça [...] (BERTRAND, 2003: 159)

Partindo desse princípio, busca-se entender como as cores, categorias do plano da expressão, na construção do discurso, estabelecem relações significativas que acabam por colaborar no processo de manipulação.

Nos livros analisados, são as cores que primeiro tocam os sentidos, trazendo à tona sensações partilhadas socialmente. Somente depois vêm as figuras, reforçando, mutuamente, os sentidos construídos pelo universo significante das cores, pois

Sempre que alguma coisa é projetada e feita, esboçada e pintada, desenhada, rabiscada, construída, esculpida ou gesticulada, a substância visual da obra é composta a partir de uma lista básica de elementos. Não se devem confundir os elementos visuais com os materiais ou o meio de expressão, a madeira ou 
a argila, a tinta ou o filme. Os elementos visuais constituem a substância básica daquilo que vemos, e seu número é reduzido: o ponto, a linha, a forma, a direção, o tom, a cor, a textura, a dimensão, a escala e o movimento. Por poucos que sejam, são a matéria-prima de toda informação visual em termos de opções e combinações seletivas. A estrutura da obra visual é a força que determina quais elementos visuais estão presentes, e com qual ênfase essa presença ocorre. (DONDIS, 2000, p. 51)

A cor, substância básica dos objetos visuais, deve ser analisada, do ponto de vista de sua força discursiva, pois, como se disse anteriormente, o contato é realizado primeiramente pela cor, apesar de as figuras e as letras serem trabalhadas com esta mesma intenção fática.

Segundo vários estudos da comunicação visual, a força expressiva da cor é dependente não só de suas coerções e regras a ela inerentes, mas também de seu valor no conjunto de todas as cores. A cor age sobre o enunciatário por sua realidade sensorial. Ao atingi-lo, desperta sensações visuais criadoras de efeitos de sentido.

Tudo isso, além da escolha estar condicionada aos costumes sociais (o vestido de noivas deve ser branco, pois representa pureza), vincula-se também à intencionalidade do enunciador, ao seu querer atrair a atenção do sujeito da interpretação, para que este seja manipulado no sentido de aderir à proposta. Por isso, a construção de determinados efeitos de sentido para realizar seu intento leva em conta que a junção de cores pode provocar efeitos de harmonia, de tensão, sensação de movimento, de envolvimento, de compulsão, de repulsão, de expansão, de agressividade, sensação de vazio, de distância, de profundidade, de proximidade.

As cores que compõem a capas são: vermelho, amarelo, azul, azul-arroxeado, branco, preto, vermelho (puxado para o rosa), rosa, verde, marrom. Em relação à sua categoria, elas, além das acromáticas (branco e preto), se agrupam em matizes primários (amarelo, vermelho e azul) e em matizes secundários (roxo, rosa, verde). Dos três livros, apenas o terceiro apresenta um fundo (quase) acromático, pois, o tom que sobressai (há certo vestígio de amarelo, sobretudo próximo ao tabuleiro de xadrez) é o branco. Nos outros dois livros, o fundo é cromático (azul-arroxeado, na Capa 1, e azul, com partes esbranquiçadas, acrescida do marrom, na Capa 2).

Comparando, coloca-se de um lado, as Capas 1 e 2, fundo cromático; de outro, a Capa 3 com fundo acromático. Em relação aos primeiros, observa que a cor tende à saturação, portanto ao excesso e o terceiro, a contensão.

Dondis (2000) afirma que a saturação, que diz respeito à pureza da cor, assume a qualidade de primitiva, sendo a preferida por artistas populares e pelas crianças. De acordo com ele, a cor saturada não oferece complicação devido ao seu caráter explícito e inequívoco. Tal saturação é composta pelos matizes primários e secundários. Já as cores menos saturadas podem provocar neutralidade cromática e ausência de cor, o que pode provocar o efeito de sentido sutileza. O emprego, pois, de uma cor muito saturada provoca as emoções, a afetividade (proximidade); já o emprego de uma cor pouca saturada provoca mais distanciamento.

Desse modo, Capa 1 e a Capa 2 são mais subjetivas, com carga maior de emoção; e a Capa 3, mais objetiva, com menor carga de emoção. Essa observação é reforçada pelas figuras já analisadas. Enquanto os dois primeiros livros figurativizam o universo, o céu, as nuvens, para criar uma ambiência de mistério, de imponderabilidade, remetendo o enunciatário a questões místicas e de religiosidade, o terceiro utiliza-se de peças de um jogo considerado totalmente racional e de pleno controle, como o subtítulo da obra indica: 
Poderosas ferramentas para você planejar e atingir as metas de sua vida. As palavras-chave são planejar e meta, em contraponto aos subtítulos dos outros dois livros (Agora você vai viver a vida de seus sonhos [...]; Do sonho a conquista), que trazem a palavra-chave sonho, que evoca, segundo os dicionários, primeiro, os sentidos de fantasia, ilusão, devaneio; depois, o de ideal, aspiração, objetivo. Nas capas 1 e 2, devido à saturação e ao aglomerado de figuras, tornam-se capas mais emocionais, de maior expressividade e, portanto, de maior apelo popular.

Além desse aspecto de saturação da cor como um componente de significação, as cores empregadas implicam um procedimento persuasivo. As cores: amarelo, azul, azularroxeado, branco, preto, vermelho (tendendo para o rosa), rosa, verde, marrom, como já se evidenciou, estão agrupadas em cores primárias, secundárias e acromáticas. Essa presença evidencia um jogo entre cores quentes (vermelho, amarelo, marrom, rosa) e frias (azul e verde), mas as primeiras sobressaem às segundas.

O amarelo, segundo Dondis (2000), é uma cor muito próxima à luz e ao calor; o vermelho incide mais sobre a percepção, por ser uma cor mais ativa e emocional; o azul, ao contrário, é uma cor passiva e suave. As duas primeiras e suas variações são cores expansivas (cores quentes) e a última, tende à contração, pertencendo à categoria de cor fria. Por serem cores quentes, o vermelho e o amarelo e suas variações tendem a aproximar o enunciatário do objeto, pois são facilmente reconhecíveis e por sobressaírem às outras.

O azul, embora seja uma cor de retração e, consequentemente, não estabeleça aproximação entre os actantes livro e leitor, pelo contraste, ele reforça a expressividade das cores quentes que se encontram em primeiro plano nos dois primeiros livros. Entretanto, no terceiro, limita-se a indicar o nome do autor. Estas cores primárias, quentes e frias, em geral, têm apelo popular, sua utilização produz o efeito de sentido proximidade - por isso, segundo estudiosos da comunicação visual, são muito utilizadas para a promoção de produtos. Desse modo, na oposição cores quentes versus cores frias, as que predominam na interação entre os sujeitos da enunciação são as quentes, as quais, por seu caráter primário, tendem a produzir o efeito de subjetividade. Esse efeito varia de um livro para outro, os dois primeiros tendem mais à subjetivação e o terceiro mais à objetivação.

A cor é também escolhida segundo sua simbologia, porque toda cor é prenhe de informações perceptivas e sócio-culturais. Ela

[...] está, de fato, impregnada de informação, e é uma das mais penetrantes experiências visuais que temos todos em comum. Constitui, portanto, uma fonte de valor inestimável para os comunicadores visuais. No meio ambiente compartilhamos os significados associativos da cor das árvores, da relva, do céu, da terra e de um número infinito de coisas nas quais vemos as cores como estímulos comuns a todos. E a tudo associamos um significado. Também conhecemos a cor em termos de uma vasta categoria de significados simbólicos. O vermelho, por exemplo, significa algo, mesmo quando não tem nenhuma ligação com o ambiente. $O$ vermelho que associamos à raiva passou também para a "bandeira (ou capa) vermelha que se agita diante do touro". O vermelho pouco significa para o touro, que não tem sensibilidade para a cor e só é sensível ao movimento da bandeira ou capa. Vermelho significa perigo, amor, calor e vida, e talvez mais uma centena de coisas. Cada uma das cores também tem inúmeros significados associativos e simbólicos. Assim, a cor oferece um vocabulário enorme e de grande utilidade para o alfabetismo visual. (DONDIS, 2000, p. 64-65) 
A percepção da cor é o mais emocional dos elementos específicos do processo visual, sua expressividade permite que se intensifique ou não a informação. Seu significado simbólico é universalmente compartilhado por meio de experiências, por isso, apresenta um valor específico. As cores, geralmente, por um processo de contiguidade, estão ligadas, quase que naturalmente a um significado, dependendo do contexto comunicativo. Tais significados culturais das cores evidenciam que as selecionadas para o livro - vermelho e suas variações, amarelo, branco, verde - evocam sempre qualidades eufóricas, excetuando-se o marrom, que traz certa carga negativa, uma vez que está associada aos sentimentos de pesar e de melancolia. Tal cor está presente na Capa 2, em que se figurativiza um caminho de pedras, o qual, como já se viu antes, constitui o lugar discursivo disforizado, local em que se encontra o enunciatário.

Chevalier e Gheerbrant (2002) afirmam que todo objeto pode ser revestido de valor simbólico, e aqui, inclui-se o objeto cor, ressaltando-se que para os autores, símbolo, por sua condição de afetividade e dinamismo, transcende o significado sem aboli-lo, mas fica à mercê da interpretação, sendo, portanto, da ordem da subjetividade.

É necessário reafirmar que aludir ao símbolo não é pretender uma análise semiológica ou, mesmo, uma análise transcendental, a qual romperia os limites de um olhar semiótico. Mas como o princípio norteador do trabalho é o de que, no nível discursivo, especificamente, na esfera comunicacional, em que se observa a relação entre o enunciador e o enunciatário, estratégias discursivas são utilizadas a fim de fazer crer e fazer aderir a uma tese enunciada; compreende-se a utilização de símbolos com valor místico, mítico e até religioso como uma estratégia da enunciação que conhece seu enunciatário e a ele ajusta os procedimentos persuasivos.

A seguir apresentam-se algumas simbologias, pretendendo mostrar, certas relações que parecem ocorrer nas três capas.

Tendo como parâmetro o Dicionário de Símbolos (2002), tem-se que o amarelo representa a luz de ouro que se torna um caminho de comunicação, um mediador entre os homens e os deuses. Está associado ao mistério da renovação e remete sempre ao poder dos príncipes, dos reis e monarcas. Isso parece condizer muito com o discurso das capas 1 e 2 que se utilizam desta cor no título e subtítulo - mas ela também está presente na Capa 3, nas pedras de xadrez.

O vermelho é considerado como símbolo fundamental do princípio da vida, devido à sua força, poder, brilho, incita à ação. É lugar da batalha, instinto de poder. Sua presença é marcante na Capa 1, especificamente, no título. O rosa simboliza perfeição acabada, uma realização sem defeito, a taça da vida, a alma, o coração, o amor. Tal cor está presente na Capa 3, como fundo da figura cavalo e também na Capa 1(vermelho-rosado).

$\mathrm{O}$ verde, segundo o dicionário, fica situado entre o azul e o amarelo, é uma cor humana que tranqüiliza e simboliza a volta da esperança, por esconder um segredo, remete a um conhecimento profundo, oculto das coisas e do destino; é a imagem das profundezas. Ela está presente na Capa 3, como fundo da figura torre inclinada.

O azul é uma cor profunda, é a mais imaterial das cores, provoca um clima de irrealidade ou de super-realidade; ela separa os homens dos deuses. Ela está presente nas três capas, mas com presença maior nas capas 1 e 2 (nesta é azul-arroxeado), figurando como pano de fundo e representando o céu e o universo.

O branco é a cor do candidato (candidus: aquele que vai mudar de condição), da revelação, da graça, da transfiguração e da manifestação de Deus; está relacionada ao ouro. Ela está presente nas três capas. Na Capa 3, é pano de fundo. 
Prepondera, portanto, a presença de conteúdos cristalizados, referencializadores, que remetem a um discurso místico e religioso, pois se pretende criar o efeito de mistério, de imponderável e, ao mesmo tempo, um discurso mais racional, no sentido dado por Jung (1964), que vê o símbolo como o elemento que funde contradições. Além disso, produz-se o reconhecimento das coisas, por meio do qual o enunciatário se identifica, pois estão discursivizados simulacros de seus problemas pessoais, profissionais etc. A escolha da cor, seus arranjos, modo de apresentação estabelecem e intensificam esse jogo de identidade (e reconhecimento).

\section{Gênero capas de livros de autoajuda: considerações finais}

Pelas análises, observou-se que a parte eufórica da capa sempre está vinculada à categoria topológica alto, e a disfórica, à categoria baixo. Não houve subversão dessa ordem, o que indica padronização, e, portanto, um processo de simbolização. Dito de outro modo, o sistema semissimbólico não sobredetermina o sistema simbólico, no sentido que Floch (1990) dá, ao chegar à conclusão de que, em alguns anúncios publicitários que lhe serviram de corpus de análise, os sistemas simbólicos são reorganizados e re-explorados de modo a constituírem sistemas semissimbólicoss. O que não ocorreu na configuração das capas. Dessa forma, todas as capas apresentaram imagens simbólicas, pois sempre remetem à interpretação única, reforçada sempre pelos enunciados verbais, aos quais estavam, no contexto da capa, associados e identificados.

Com exceção da Capa 3, as imagens das outras duas veiculam conteúdos místicos e religiosos (na verdade religiosidade, pois não se refere especificamente a um deus de determinada religião). Em relação a esses tipos de conteúdos, notou-se que os elementos visuais (cores, formas) de algum modo remetem a conteúdos simbólicos registrados no Dicionário de Símbolos, o que denota a preocupação do enunciador em trabalhar com determinados elementos, ao quais dizem respeito a um tipo de enunciatário específico.

Assim, a utilização de figuras e cores que remetem sempre ao discurso místico e religioso (esoterismo) é uma estratégia de construção de vínculos identitários entre os enunciadores (processo de incorporação), por meio da qual se estabelece a promessa de transformação do sujeito da interpretação, do qual é simulado o provável e desejável deslocamento da posição inferior para a posição superior, cujo instrumento (cognitivo) é o livro, que deverá ser comprado e lido.

\section{REFERÊNCIAS}

AGUILAR, G. H. (org.) Figuras y estratégias - En torno a uma semiótica de lo visual. Madri: Siglo XXI editores, s/d.

BARTHES, R. Crítica e verdade. São Paulo: Perspectiva, 2003.

BERTRAND, D. Caminhos da semiótica literária. Trad. Grupo CASA. Bauru, SP: EDUSC, 2003.

CHEVAliER, J. \& GHEERBRANT, A. Dicionário de símbolos. São Paulo: José Olímpio, 2002.

DONDIS, D. A. Sintaxe da linguagem visual. São Paulo: Martins Fontes, 2000.

DORIA JÚNIOR, J. Lições para vencer. São Paulo: Ed. Gente, 2001.

FLOCH, J.M. Semitique, marketing et communication: Sous kes signism les stratégies. Paris: Presses Universitaires de France, 1990. 
GREIMAS, A. J. \& COURTES, J. Dicionário de Semiótica. São Paulo: Cultrix, (1979).

GREIMAS, A. J. (Org) Ensaios de semiótica poética. Trad. Heloysa de Lima Dantas. São Paulo: Cultrix, EDUSP, 1975.

LOPES, E. A palavra e as coisas: ensaio sobre a teoria e a prática da literatura. Campinas, São Paulo: UNESP, 1993.

MAINGUENEAU, D. Análises de textos de comunicação. São Paulo: Cortes, 2004.

OLIVEIRA, A. C. e TEIXEIRA, L. Linguagens na comunicação: desenvolvimentos de semiótica sincrética. São Paulo: Estação das Letras e Cores, 2009.

PEREIRA, J. N. Gênero autoajuda: estratégias linguístico-discursivas. 2005. 199f. Tese (Doutorado em Língua Portuguesa). PUC-SP, São Paulo.

PERELMAN \& OLBRECHTS-TYTECA. Tratado de argumentação - a nova retórica. São Paulo: Martins Fontes, 2002.

SANTOS, A.H. Você pode conseguir o que quer - Poderosas ferramentas para você planejar e atingir as metas de sua vida, São Paulo: Vozes, 2001.

SAUSSURE, F. Curso de Linguística Geral. São Paulo: Cultrix, 1973.

TREVISAN, L. O Poder infinito da sua mente. Rio Grande do Sul: Ed. Mente, 1980.

Recebido em: 21/04/12

Aprovado em: 10/11/12 